\title{
Prática pedagógica criativa: análise de produções brasileiras a partir da psicologia histórico-cultural
}

\author{
Creative pedagogical practice: analysis of brazilian productions from \\ historical-cultural psychology
}

\section{Práctica pedagógica creativa: análisis de producciones brasileñas a partir de la psicología histórico-cultural}

\author{
Marilda Gonçalves Dias Facci ${ }^{1}$ \\ http://orcid.org/0000-0001-7443-490X \\ Kleia Naiara Peixoto 2 \\ http://orcid.org/0000-0003-1863-2578
}

\begin{abstract}
Resumo: O objetivo deste artigo é apresentar resultados de uma pesquisa que teve como finalidade analisar como a criatividade do professor tem sido compreendida atualmente, tendo como referência a Psicologia Histórico-Cultural. A metodologia utilizada foi a pesquisa bibliográfica, tomando como referência produções indexadas no período de 2010 a 2015, em três bases eletrônicas: a Biblioteca Digital Brasileira de Teses e Dissertações; o Scientifc Eletronic Library Online - Scielo; e o Google Acadêmico. A primeira parte do artigo destina-se a explanação do desenvolvimento da criatividade, tal como posta pelos teóricos da Psicologia Histórico-Cultural. A seguir, discorreremos sobre a forma como alguns autores, mencionados na bibliografia pesquisada, compreendem o desenvolvimento da criatividade, assim como o que estes autores consideram como fatores determinantes a criatividade na prática pedagógica. $\mathrm{Na}$ sequência, serão apresentados exemplos de práticas pedagógicas tidas como criativas. Informações a respeito da qualidade das apropriações dos professores e a consequência das mesmas sobre a possibilidade de atuações criativas serão colocadas no tópico posterior. Concluindo, analisamos que, geralmente, o desenvolvimento da criatividade é considerando como resultado de mero esforço individual, sem que haja uma discussão aprofundada sobre quais os fatores responsáveis por sua existência, ou ausência, e de que modo estes se desenvolvem. Defendemos a criatividade como função psicológica superior, portanto, esta deve ser compreendida como uma capacidade que se desenvolve a partir da apropriação da cultura elaborada historicamente pelos homens e não apenas pela presença ou ausência de um conjunto de comportamentos ligados a um estereótipo.
\end{abstract}

Palavras-chave: Criatividade. Professor. Psicologia Histórico-Cultural.

1 Doutora em Educação Escolar pela UNESP-Araraquara e Pós-doutorado em Psicologia Escolar e do Desenvolvimento Humano pelo Instituto de Psicologia da USP. Professora do Departamento de Psicologia e do Programa de Pós-Graduação em Psicologia da Universidade Estadual de Maringá.

E-mail: marildafacci@gmail.com

2 Graduada em Psicologia pela Universidade Paulista (2013); especialista em Psicologia Histórico-Cultural (UEM- 2016); especialista em Transtorno do Espectro Autista (2017); Mestre em Psicologia pela Universidade Estadual de Maringá - UEM (2017).

E-mail: naiarapeixoto@msn.com 


\begin{abstract}
The result of a research on the manner teachers' creativity is currently understood, is provided, foregrounded on Historical and Cultural Psychology. A bibliographical research has been performed with regard to productions indexed between 2010 and 2015, in three electronic databases, namely, The Brazilian Digital Library of Theses and Dissertations, Scientific Electronic Library Online (Scielo), and Academic Google. The first section deals with the development of creativity posited by Historical and Cultural Psychology. The manner some authors, mentioned in the bibliography, comprehend the development of creativity and what they consider determining factors of creativity in pedagogical practice is discussed. Examples of creative pedagogical practices are given. Information follows on the quality of appropriations by teachers and their consequences on the possibility of creative practices. Results show that, as a rule, the development of creativity is the result of mere individual effort without any in-depth discussion on the factors that cause its presence or absence and the manner they develop. The author holds that creativity, as a higher psychological function, should be understood as the capacity developed through the appropriation of historically elaborated culture and not as the presence or absence of a set of behavior types linked to a stereotype.
\end{abstract}

Keywords: Creativity. Teacher. Historical-Cultural Psychology.

Resumen: En este artículo se tuvo por objetivo presentar resultados de una investigación que tuvo finalidad analizar cómo la creatividad del profesor ha sido comprendida actualmente, teniendo como referencia la Psicología Histórico-Cultural. La metodología utilizada fue la investigación bibliográfica, tomándose como referencia producciones indexadas en el período de 2010 a 2015 en tres bases electrónicas: la Biblioteca Digital Brasileña de Tesis y Tesinas; el Scientifc Eletronic Library Online - Scielo; y el Google Académico. La primera parte del artículo se destina a la explanación del desarrollo de la creatividad tal como puesta por los teóricos de la Psicología Histórico-Cultural. A seguir, explanaremos sobre la forma como algunos autores, mencionados en la bibliografía investigada, comprenden el desarrollo de la creatividad, así como lo que estos autores consideran como factores determinantes de la creatividad en la práctica pedagógica. En la secuencia serán presentados ejemplos de prácticas pedagógicas consideradas como creativas Informaciones a respeto de la calidad de las apropiaciones de los profesores y la consecuencia de ellas sobre la posibilidad de actuaciones creativas serán colocadas en el tópico posterior. Concluyendo analizamos que, generalmente, el desarrollo de la creatividad es considerando como resultado de puro esfuerzo individual, sin que haya una discusión profundizada sobre cuales los factores responsables por su existencia o ausencia y de qué modo estos se desarrollan. Defendemos la creatividad como función psicológica superior, por lo tanto, esta debe ser comprendida como una capacidad que se desarrolla a partir de la apropiación de la cultura elaborada históricamente por los hombres y no solo por la presencia o ausencia de un conjunto de comportamientos ligados a un estereotipo.

Palabras clave: Creatividad. Profesor. Psicología Histórico-Cultural.

\title{
1 INTRODUÇÃO
}

Este artigo resulta de pesquisa bibliográfica acerca da temática da criatividade dos professores e fundamenta suas análises nos pressupostos da Psicologia Histórico-Cultural. Em pesquisa realizada anteriormente por Peixoto (2016), verificou-se que a área da educação é a que mais tem produzido material a respeito do desenvolvimento da criatividade. Apesar da necessidade de desenvolvimento da criatividade do professor ter sido constantemente ressaltada, Peixoto constatou que a maioria das produções analisadas tratou de discutir a criatividade do aluno. Notou também que é reduzido o número de produções que discutem a criatividade a partir da Psicologia Histórico-Cultural. Por identificarmos esta demanda, temos como objetivo, neste artigo, apresentar resultados de uma pesquisa que teve como finalidade analisar como a criatividade do professor tem sido compreendida atualmente, tendo como referência a Psicologia Histórico-Cultural. 
O papel que o ensino exerce no desenvolvimento psíquico dos indivíduos, principalmente as crianças, não pode ser ignorado. Ao se inserirem em uma atividade educativa formal, os sujeitos se apropriam de conhecimentos que não lhe são acessíveis em outras atividades. Tais conhecimentos complexificam seu pensamento e the possibilita relacionar de um novo modo com a realidade. Sabe-se que a transmissão destes conteúdos resulta em uma tarefa complexa e que a eficácia das formas utilizadas para atingir tal objetivo é a todo o momento colocada à prova. São nestes momentos em que a capacidade criativa do professor é exigida. Sabemos que o sucesso do aprendizado ultrapassa as questões relativas ao fato do professor ser ou não criativo, entretanto, compreendemos que faz parte de seu processo a identificação e o desenvolvimento de soluções para as questões impeditivas ao domínio dos conteúdos pelos alunos.

Neste trabalho, para que o leitor compreenda sob qual perspectiva realizaremos a análise dos dados encontrados, apresentaremos, na primeira parte, uma explanação a respeito do desenvolvimento da criatividade, tal como posta pelos teóricos da Psicologia Histórico-Cultural. A seguir, apresentaremos o resultado da pesquisa sobre o tema criatividade do professor no Scientific Electronic Library - Scielo, na Biblioteca Digital Brasileira de Teses e Dissertações e no Banco de dados do Google Acadêmico. Ao final exporemos questões concernentes a qualidade de apropriação teórica dos professores e a relação destas com a possibilidade de desenvolvimento de práticas pedagógicas criativas.

\section{CRIATIVIDADE E PSICOLOGIA HISTÓRICO-CULTURAL}

A constituição social do indivíduo é o eixo central da Psicologia Histórico-Cultural. É a partir dessa premissa que todas as capacidades humanas são explicadas por seus teóricos. Entende-se, a partir dos pressupostos dessa teoria, que o desenvolvimento psíquico humano resulta de sua história natural e social, sendo a primeira o ponto de partida em que funções psicológicas elementares foram desenvolvidas, registradas e transmitidas a todos os indivíduos da espécie. Tais funções estabelecem relação de dependência com a maturação orgânico-cerebral e caracterizam-se por sua imediaticidade e involuntariedade. Funções desta categoria podem ser encontradas também em mamíferos superiores (VIGOTSKI, 2000).

As funções desenvolvidas na história social são consideradas superiores e desenvolvem-se apenas nos homens. Resultam da apropriação dos instrumentos materiais e simbólicos, desenvolvidos ao longo da história da humanidade, a que o sujeito teve acesso via relações socioculturais, ao longo de sua história individual. Para Vigotski (2000), o desenvolvimento de funções psicológicas superiores possibilita que o homem controle intencio- 
nalmente seu comportamento, ou seja, que aja de forma consciente e não mais apenas de forma reflexa. A criatividade, por ser uma capacidade desenvolvida apenas em humanos, encaixa-se nesta segunda categoria de funções.

Vigotski (2009) ressalta a importância da criatividade para a história do gênero humano. O autor afirma que é esta capacidade que possibilita ao homem sua constante evolução. Quanto a isto, ele analisa:

Se a atividade do homem se restringisse à mera reprodução do velho, ele seria um ser voltado somente para o passado, adaptando-se ao futuro apenas na medida em que este reproduzisse aquele. É exatamente a atividade criadora que faz do homem um ser que se volta para o futuro, erigindo-o e modificando o presente (VIGOTSKI, 2009, p. 14).

Mas o que diferencia o homem dos demais animais e o habilita a desenvolver a capacidade criativa? Leontiev (1978), ao tratar do desenvolvimento do psiquismo, apresenta-nos uma trajetória de estágios desenvolvimentais que nos possibilita compreender as diferenças entre o psiquismo humano e o psiquismo de outras formas de vida. O autor afirma que o início deste desenvolvimento se dá na fase denominada por ele de Estádio do psiquismo sensorial elementar. Tal período caracteriza-se pelo uso isolado dos órgãos dos sentidos em que os organismos são, por isso, capazes apenas de diferenciar as sensações, estando seu corpo voltado somente a perceber os estímulos que o rodeia. Com a passagem a vida terrestre, alguns seres desenvolveram órgãos motores de atividade exterior, o que favoreceu a captura de presas, alterou a sua relação com o mundo exterior e possibilitou o surgimento do sistema nervoso primitivo. Entretanto, esta transformação orgânica não alterou a estrutura da atividade, ou seja, não alterou a relação destes com meio externo. Esta permaneceu a ser regulada por um estímulo externo e mediada por apenas um órgão do sentido, não permitindo, deste modo, a percepção da totalidade do objeto. Este estágio do psiquismo pode ser verificado em insetos, vermes, moluscos, aracnídeos e crustáceos.

A etapa posterior deste desenvolvimento é denominada de Estádio do psiquismo perceptivo. Neste estágio há uma modificação estrutural da atividade, ou seja, da relação com o meio externo e o animal passa a se relacionar não mais apenas com o objeto, mas com as condições do meio em que este lhe aparece. É nesta etapa que, de acordo com Leontiev (1978), transformações orgânicas, como o desenvolvimento de órgãos do sentido e a reorganização do sistema nervoso central e a formação do cérebro anterior, acontecem. Aparece também nesse estágio o que o autor denomina: hábitos. Estes correspondem a reorganização mnemônica destes animais, que proporciona a fixação de operações em sua atividade. Pertencem a esta classe de animais répteis, mamíferos e anfíbios. 
O estágio posterior é o Estádio do Intelecto, no qual os animais conseguem resolver problemas a partir de ensaio e erro. Estes devem tal feito ao desenvolvimento do córtex pré-frontal, que ocupa a posição de órgão principal de regulação do comportamento. Este estágio desenvolvimental é característico de mamíferos superiores. Uma característica fundamental a ser destacada é que, nos níveis anteriores a atividade é realizada em um único processo, ou seja, os organismos são estimulados por algum elemento externo via órgãos dos sentidos e, então, respondem a estes de maneira direta. Com o desenvolvimento do intelecto, a atividade passa a ser realizada em duas fases. Estas podem ser compreendidas como fase de preparação e a fase de efetivação ou alcance do objetivo.

A existência de uma preparação para ao alcance de objeto (primeira fase), é interpretada por Martins (2011) não como tentativas fortuitas de alcance do objetivo, mas tentativas de operações. A autora afirma que para os mamíferos superiores "a operação deixa de estar subordinada apenas à atividade que atende a um fim específico" (MARTINS, 2011, p. 24), o que possibilita a transferência das operações a situações semelhantes. Entretanto, apesar do avanço alcançado, o psiquismo, nesta fase, permanece regido pelas leis biológicas.

Percebe-se, com a exposição das diferentes formas de relação do animal com o meio, que o reflexo da realidade é a ela condicionado. Sendo assim, para compreendermos a diferença entre o psiquismo humano e as demais formas aqui mencionadas, é necessário explicitar sob quais condições materiais, segundo a compreensão da Psicologia Histórico-Cultural, esse salto qualitativo de orientação e relação com a realidade foi passível de desenvolvimento e onde a categoria Criatividade aparece neste processo.

À diferença dos animais que apenas empregam os instrumentos, o homem também os prepara, o que exige que o indivíduo antecipe mentalmente suas ações e que conheça a finalidade do objeto a preparar. $\mathrm{O}$ reconhecimento do emprego futuro dos instrumentos pode ser considerado como primeiro surgimento da consciência, o que muda radicalmente o comportamento humano. Apesar do uso de instrumentos, verificado nos animais superiores, a relação que eles estabelecem com tais objetos é a de adaptação imediata ao meio, o que os mantêm sob o julgo das necessidades biológicas e não os capacita a agir para além das experiências individuais. Com a complexificação das relações sociais e as formas de produção de instrumentos, também se complexificou a atividade humana, distanciando-se cada vez mais das necessidades biológicas e se aproximando do objeto consciente de sua atividade. A forma superior de utilização de instrumentos pelos homens foi o que proporcionou o salto qualitativo em seu desenvolvimento psíquico (LEONTIEV, 1978).

Luria (1979) entende que o desenvolvimento da linguagem também exerceu papel fundamental para o salto qualitativo entre o psiquismo animal e o desenvolvimento da 
consciência. A vida gregária propiciou a divisão do trabalho e provocou a necessidade de comunicação entre os sujeitos, que, inicialmente, era entrelaçada à atividade prática e se restringia a gestos e avançou até a separação entre sons e ações. Mudanças fundamentais são atribuídas à linguagem na constituição da consciência humana. Graças ao desenvolvimento da linguagem, a atenção do homem pode ser dirigida a um objeto específico, libertando-se da imediaticidade da atenção animal, ou seja, a atenção passou a ser voluntária. A linguagem permitiu, ainda, a permanência do objeto na memória do sujeito, o que possibilitou a ele se relacionar com tal objeto mesmo este não estando em sua presença. Por fim, o desenvolvimento da linguagem proporcionou a generalização e a abstração, o que possibilitou a identificação das propriedades fundamentais dos objetos, permitindo sua categorização e diferenciação dos demais objetos existentes.

Deste modo, compreendemos que foi o desenvolvimento da consciência, desta forma superior de relação e orientação no mundo, resultado da complexificação de sua relação com a natureza, da vida gregária e do desenvolvimento da linguagem, que possibilitou ao homem analisar as relações entre os objetos e fenômenos da realidade, mesmo que estes estejam ausentes, o que permitiu ao homem criar.

Vigotski (2009) divide a atividade humana em duas categorias: atividade reprodutiva e atividade criadora. A primeira diz a respeito às atividades em que o indivíduo se limita a reproduzir os comportamentos anteriormente vividos. Esta categoria de atividade se liga de modo íntimo a memória e tem como base a plasticidade cerebral. Para o autor, a capacidade que nosso cérebro possui de alterar sua estrutura e conservar as marcas dessa modificação é o que nos possibilita reproduzir as experiências anteriormente vividas. A segunda forma de atividade, a atividade criadora, é definida por Vigotski (2009) como "aquela em que se cria algo novo. Pouco importa se o que se cria é algum objeto do mundo externo ou uma construção da mente ou do sentimento, conhecida apenas pela pessoa em que esta construção habita e se manifesta" (VIGOTSKI, 2009, p. 11). Ao contrário da primeira forma de atividade, nesta, o sujeito volta-se ao futuro, não se prendendo aquilo que já experienciou. Além da plasticidade cerebral, esta forma de atividade apoia-se na imaginação.

Petrovski (1980) assevera que as imagens conhecidas do sujeito é a base para a criação de novas imagens no processo imaginativo, mesmo que estas últimas sejam as mais absurdas e inesperadas. Vigotski (2009), em concordância com o que assegura Petrovski (1980), afirma que há entre imaginação e realidade quatro formas de relação. $O$ autor esmiúça estas relações, conforme veremos a seguir.

Primeira: A imaginação sempre se constituirá de elementos reais, presentes na experiência anterior do indivíduo. Aquele que imagina não inventa a partir do nada, ele apenas 
recombina elementos da sua realidade e somente sua recombinação pode ser fantasiosa. Vigotski (2009) entende ainda que a riqueza da imaginação estabelece correlação direta com o acúmulo de experiência individual. Deste modo, quanto mais rica a experiência do indivíduo, mais elementos ele terá para imaginação. Em alguns momentos, na aparência, imaginação e memória podem se confundir. Rubinstein (1967), no entanto, ressalta que a característica fundamental da memória, consiste na conservação mais fidedigna possível da experiência vivida pelo sujeito; enquanto que à imaginação cabe a transformação desta realidade.

Segunda: É mais complexa, pois não se refere mais apenas a uma recombinação fantasiosa dos elementos da realidade. Esta forma diz respeito à combinação dos elementos reais formando, na imaginação, um cenário que verdadeiramente existe na realidade. Este processo é instigado pela narrativa de outros e se baseia em elementos da experiência pessoal de quem imagina. Assim, ao ouvir um relato sobre uma expedição no Alasca, por exemplo, o sujeito consegue recriar mentalmente tal cenário, mesmo sem nunca termos visitado aquele lugar; ou quando the conta sobre um prato típico que experimentou em uma comunidade indígena pouco conhecida, o sujeito consegue imaginar o sabor da refeição. Conferimos esta capacidade aos conhecimentos prévios adquiridos pelo indivíduo. Nos exemplos mencionados, tal capacidade pode ser atribuída a distinção entre frio e calor, saber o que seja neve, mar, geleiras, etc. Bem como o conhecimento do que seja algo doce, salgado, apimentado, seco, caudaloso. Os sujeitos podem ainda comparar objetos e situações a ele relatados com os objetos e situações que conhece. Por ser assim, esta forma de imaginação se subordina a primeira, pois é necessário uma gama considerável de experiência para que, a partir delas, as novas imagens mentais sejam construídas. Esta forma de imaginação só é possível devido os relatos de experiência de outrem, o que, certamente, propicia uma ampliação dos conhecimentos e experiências daquele que recebe as informações e imagina as situações e objetos.

Se ninguém nunca tivesse visto nem descrito o deserto africano e a Revolução Francesa, então uma representação correta desses fenômenos seria completamente impossível para nós. É devido ao fato de que minha imaginação, nesses casos, não funciona livremente, mas é orientada pela experiência de outrem, atuando como se fosse por ele guiada, que se alcança tal resultado, ou seja, o produto da imaginação coincide com a realidade (VIGOTSKI, 2009).

Pelos exemplos mencionados, nota-se a fundamental influência da linguagem no processo imaginativo. A apropriação da linguagem provoca a reorganização das funções psicológicas no homem e amplia seu universo, passando o sujeito a não mais necessitar 
do contato material direto com as coisas, o que possibilita um avanço mnemônico e a complexificação dos processos de regulação de suas ações. Deste modo, tal como afirma Luria (2008), os homens "podem mesmo lidar com objetos 'ausentes e assim 'duplicar o mundo" (LURIA, 2008, p. 24). Dessa forma surge uma nova fonte de imaginação, que serve de base aos processos criativos complexos.

Terceira: É de caráter emocional e se apresenta de duas maneiras. Em uma delas, os sentimentos e emoções tendem a "exibir-se em imagens conhecidas correspondentes a esse sentimento" (VIGOTSKI, 2009, p. 25). Esta forma de imaginação é guiada pelas emoções que sentimos em determinado momento. Assim, para além das reações físicas, como a sudorese, tremor, palpitação cardíaca etc., as emoções e sentimentos se expressam de maneira interna, selecionando nossas ideias e impressões a respeito das coisas. Este fenômeno, Vigotski (2009) denominou de Lei da dupla expressão dos sentimentos. Se, por exemplo, somos convidados para uma festa e estamos deprimidos, tendemos a imaginar a festa como desanimada, chata, que as músicas serão ruins. Se do contrário, estamos felizes, a tendência é nos imaginarmos dançando alegremente, conversado com as pessoas, nos divertindo.

Os sujeitos, sob a influência dos sentimentos, podem ainda selecionar e combinar os elementos da realidade que isoladamente não mantém relação externa alguma, mas internamente estabelecem sentido. Se dizemos estar 'tudo azul', isso pode ser compreendido como: está tudo ótimo. Essa influência das emoções sobre a forma combinatória de imaginação é denominada por Vigotski (2009) de Lei do signo emocional comum. Quanto a isso, comenta o autor:

A essência dessa lei consiste em que as impressões ou as imagens que possuem um signo emocional comum, ou seja, que exercem em nós uma influência emocional semelhante, tendem a se unir, apesar de não haver qualquer relação de semeIhança ou contiguidade explícita entre elas. Daí resulta uma obra combinada da imaginação em cuja base está o sentimento ou o signo emocional comum que une os elementos diversos que entraram em relação (VIGOTSKI, 2009, p. 26).

Ainda em relação ao caráter emocional da imaginação, ao contrário do primeiro modo de interação entre sentimento e imaginação, em que o primeiro influencia o último, aqui a relação acontece de maneira inversa, ou seja, a imaginação é que influencia os sentimentos. Vigotski (2009) denomina esse processo como Lei da realidade emocional da imaginação. Uma melodia pode suscitar em nós imaginações sobre algo, ou alguém, esta imaginação gera sentimentos, seja prazerosos ou desprazerosos; ao lermos um livro, imaginamos as cenas e por vezes sentimos raiva ou dó dos personagens; é muito comum as crianças imaginarem haver um monstro debaixo da cama e, com isso, sentirem-se ame- 
drontadas. Todas as situações citadas são irreais: o monstro debaixo da cama; as ilusões criadas por nós ao ouvirmos a música; as cenas descritas no romance, nada disso existe na realidade, no entanto, todo o sentimento provocado por essas imaginações são por nós experienciados de forma verdadeira.

Estas formas de imaginação explicitadas por Vigotski são consideradas por Petrovski (1980) como formas ativa de imaginação. O que significa que são formas de imaginação que levam a criação de algo, quer sejam criações subjetivas de sentimentos, sensações, cenários que leva o sujeito a experienciar novos conteúdos, quer seja a criação que se materializa em novos produtos que modificarão a realidade existente.

Vigotski (2009) comenta ainda sobre uma quarta forma de relação entre imagem e realidade: refere-se à forma cristalizada de imaginação. Nela, o sujeito extrai os elementos da realidade, reelabora-os mentalmente e, então, materializa um novo produto, fruto desta reelaboração. Este novo elemento, que antes não existia na realidade, passa agora a existir e a modificá-la. Tal processo ocorre em sujeitos que trabalham tanto na área técnica, com a criação de um instrumento inovador, por exemplo, um novo aparelho tecnológico que modifica a forma de comunicação entre as pessoas; ou subjetiva, a exemplo da literatura e das artes plásticas, que influenciam o modo de ser, agir e sentir daqueles que dela se apropriam.

Para atingir este último estágio, de cristalização de sua imaginação, ou seja, o da criação propriamente dita, o sujeito percorre um longo caminho que se inicia com a complexificação de sua imaginação, passando pelas condições objetivas de sua realidade até chegar à objetivação do que imaginara. "Toda atividade de imaginação tem sempre uma história muito extensa. O que denominamos de criação costuma ser apenas o ato catastrófico do parto que ocorre como resultado de um longo período de gestação e desenvolvimento do feto" (VIGOTSKI, 2009, p. 35).

O início do processo se dá com o acúmulo dos estímulos externos que o sujeito recebe através dos órgãos dos sentidos. Em seguida, o que foi acumulado passa por uma reelaboração, havendo, conforme assevera Vigotski (2009), a "dissociação e associação das impressões percebidas" (VIGOTSKI, 2009, p. 36). A dissociação é o processo em que as partes do conjunto de estímulos recebidos são separadas, fragmentadas; podendo uma de essas partes receber mais destaque que as demais; outras serem conservadas e ainda outras serem esquecidas. Atrelado ao processo de dissociação está o de modificação ou distorção. A modificação dos elementos dissociados é um processo ativo que se subordina as emoções e necessidades do sujeito. Para o autor, "exageramos porque queremos ver as coisas de forma exacerbada, porque isso corresponde à nossa necessidade, ao nosso 
estado interno" (VIGOTSKI, 2009, p. 37). A associação é a união dos elementos que compuseram o processo de dissociação, podendo ser uma união subjetiva ou objetiva. Este processo pode ser verificado nas primeira e segunda forma de relação entre imaginação e realidade, explicadas anteriormente.

Finalmente acontece o processo de cristalização da imaginação, ou seja, a materialização do que foi imaginado. O desequilíbrio e a necessidade de adaptação ao meio ocupam o primeiro lugar como fatores dos quais este processo depende. Para Vigotski (2009), "o ser completamente adaptado ao mundo nada desejaria, não teria nenhum anseio e, é claro, nada poderia criar. Por isso, na base da criação há sempre uma inadaptação da qual surge necessidades, anseios e desejos" (VIGOTSKI, 2009, p. 40).

Ante uma necessidade, nosso cérebro inicia um processo de recuperação das experiências vividas e impulsiona a imaginação. No entanto, além de desenvolver a capacidade combinatória de imaginação, para que o sujeito possa efetivar de fato aquilo que imaginou, além dos conhecimentos acumulados a respeito do que se relaciona à sua elaboração mental, é de fundamental relevância o meio circundante e o tempo histórico em que o sujeito se encontra. Não podemos esperar que num ambiente que proporciona pouca oportunidade de acesso à cultura possa, simplesmente, emergir dos indivíduos elaborações complexas, nem que estes tenham condições de apresentar soluções aos problemas, sem antes o gênero humano ter avançado a ponto de produzir conhecimentos e objetos que propiciassem a materialização dos mesmos.

Qualquer inventor, mesmo um gênio, é sempre fruto de seu tempo e de seu meio [...] A criação é um processo de herança histórica em que cada forma que sucede é também determinada pelas anteriores. Dessa maneira também explica-se a distribuição desproporcional de inovadores e de pessoas criadoras em diferentes classes. As classes privilegiadas detêm um percentual incomensuravelmente maior de inventores na área da ciência, da técnica e das artes porque é nessas classes que estão presentes todas as condições necessárias para a criação (VIGOTSKI, 2009, p. 42).

\footnotetext{
Assim, compreende-se a criatividade como uma função psicológica complexa, mas passível de desenvolvimento a todos os indivíduos da espécie humana; função esta que estabelece relação direta com a riqueza das apropriações dos indivíduos, podendo seus produtos serem compreendidos somente em relação com a sociedade e o tempo histórico em que foram desenvolvidos.
}

Tal como a imaginação, o pensamento também é fundamental à criatividade. É por meio do pensamento que o homem infere, relaciona e reelabora os fenômenos da realidade, pois não basta o sujeito imaginar, para que ele alcance a objetivação, faz-se necessário 
que ele reflita sobre a relação das partes que compõe e as possibilidades de realização daquilo que imaginara (GUREVICH, 1978). Para Petrovski (1980), o pensamento é fundamental não apenas a resolução, mas a formulação de novos problemas.

Petrovski (1980) afirma que o pensamento é, em primeiro lugar, análise, síntese e generalização. A análise é o processo de divisão do objeto ou fenômeno, que possibilita a identificação de seus diferentes aspectos e propriedades e as conexões e relações entre seus elementos. Esta se diferencia em dois tipos: na divisão mental do todo em suas partes, como por exemplo, a divisão de uma árvore em raiz, caule e copa; e/ou na separação do todo, segundo suas qualidades ou aspectos, como a separação de objetos por cor, tamanho, ou de pessoas por características de personalidade, por idioma e outras infinitas qualidades (GUREVICH, 1978; PETROVSKI, 1980).

A síntese é o processo que possibilita a correlação entre os componentes do objeto, ou fenômeno, dissociados no processo de análise, propiciando, deste modo, a compreensão de seu funcionamento. Tal como a análise, o processo de síntese se diferencia em duas formas análogas: uma das formas se realiza quando unimos mentalmente as partes em um todo, como quando construímos mentalmente um mecanismo qualquer, ou recompomos idealmente uma cena teatral; a outra forma se realiza quando, a partir da descrição de um objeto, ou fenômeno, o representamos mentalmente. Apesar de antagônicos, os processos de análise e síntese sempre se inter-relacionam (GUREVICH, 1978).

A capacidade de generalização é o que possibilita distinguir um objeto dos demais e inseri-lo em uma categoria, identificando características essenciais que o fazem ser aquilo que é (GUREVICH, 1978; VIGOTSKI, 2010). Para alcançar a generalização, o sujeito necessita se apropriar dos conceitos. Vigotski (2001) diferencia duas categorias de pensamentos por conceito: os conceitos espontâneos e os científicos. Os primeiros se desenvolvem na cotidianidade e, por meio deles, o sujeito atribui significado aos objetos e fenômenos da realidade, orientado pelas suas semelhanças imediatas, e/ou de maneira espontânea, caracterizando, deste modo, este processo como isento de percepção consciente das relações existentes entre as partes que os compõem. Já com o desenvolvimento da segunda categoria de conceitos, o sujeito é capaz de perceber e estabelecer relações entre o que não pode captar dos objetos via órgão dos sentidos. O teórico russo ressalta ainda que as duas categorias de conceitos estão interligadas e se influenciam, compondo um processo único.

Pensamento e imaginação estão estreitamente vinculados. O que há de comum entre a imaginação e o pensamento é que ela, assim como o pensamento, também surge ante a uma situação problemática, um fato desconhecido, e é motivada por necessidades. En- 
tretanto, apesar dessa proximidade, existem diferenças entre estes fenômenos. A diferença está na forma como as representações do objeto da necessidade são produzidas. Enquanto a imaginação produz imagens concreto-figurativas, ou seja, combinações de imagens baseadas nas formas reais dos objetos, captadas pelos órgãos dos sentidos; o pensamento trabalha e produz imagens por meio dos conceitos - pela combinação dos conceitos e suas generalizações (PETROVSKI, 1980).

Deste modo, compreendemos que a resolução de problemas exige, simultaneamente, tanto a participação da imaginação quanto do pensamento, porém, a imaginação aparece em maior grau quando o nível de indeterminação da situação problemática também é maior; e o pensamento opera quando as determinações do problema estão claras. Petrovski (1980) traz a seguinte contribuição para essa discussão:

É obvio que não é necessário usar a imaginação naquela zona de fenômenos cujas leis fundamentais são conhecidas. No entanto, quando os antecedentes da situação são muito próximos, é difícil obter a resposta por meio do pensamento, então entra em vigor a fantasia (...). As vias de solução assinaladas pela imaginação são geralmente pouco precisas, pouco rigorosas. No entanto, a necessidade de existir e atuar em um meio de informação incompleta conduz à formação do aparato imaginativo na pessoa. Devido a que no mundo circundante sempre haverá campos não estudados, o aparato da imaginação sempre será útil (PETROVSKI, 1980, p. 322).

Podemos, deste modo, compreender que a imaginação é base para o pensamento conceitual, logo, a imaginação existe no conceito. O que diferencia o pensamento por conceito dos processos imaginativos é o fato de que o pensamento conceitual ser um desenvolvimento social dos processos básicos de geração de imagens (imagens concreto-figurativas). $\mathrm{O}$ fato de $\mathrm{o}$ indivíduo retroceder aos processos de imaginação figurativa diante de uma situação problemática significa que este não tem desenvolvido os conceitos de forma suficiente à sua resolução.

Assim sendo, concluímos que o papel da imaginação é prospectar, projetar aquilo que ainda não existe. A criatividade se inicia com um problema, que impulsiona a imaginação, esta projeta aquilo que ainda não existe; e o pensamento põe à prova os processos para alcançar esse produto, viabilizando assim sua materialização. No entanto, é importante esclarecer que outras funções psicológicas também participam do processo de desenvolvimento da criatividade e que a decisão por optarmos discorrer sobre o pensamento justifica-se pelo papel de destaque, dado pelos autores da Psicologia Histórico-Cultural, no que tange ao planejamento e preparo das ações, que visam à objetivação daquilo que foi imaginado pelos sujeitos. 


\section{PERSPECTIVAS ADOTADAS PELOS AUTORES DE PRODUÇÕES BRASILEIRAS PARA A COMPREENSÃO DA CRIATIVIDADE DO PROFESSOR NA PRÁTICA PEDAGÓ- GICA}

Objetivando conhecer a produção atual de trabalhos brasileiros a respeito da criatividade do professor, realizamos uma busca por teses, dissertações e artigos que versassem sobre a temática entre os anos de 2010-2015. Tal busca se deu em três bancos de dados: a Biblioteca Digital Brasileira de Teses e Dissertações; o Scientifc Eletronic Library Online Scielo; e o Google Acadêmico. Para tal, utilizamos combinações de descritores, buscando pelas correspondências dos termos no título e resumos dos trabalhos: Criatividade + professor; Criativo + professor; Criatividade + sala de aula. Obtivemos um resultado inicial de 84 produções científicas, das quais, após análise, foram selecionadas 12 , sendo quatro teses, duas dissertações e seis artigos. Os critérios adotados para que as produções fossem selecionadas foram de que estas estivessem em língua portuguesa e discutissem apenas a criatividade do professor ou na atividade pedagógica, excluindo aqueles que, apesar de conter a combinação de descritores, versavam sobre o desenvolvimento da criatividade do aluno. Para a exposição dos resultados, elegemos alguns eixos de análise, apresentados a seguir:

\subsection{Teóricos utilizados para fundamentar as produções científicas}

Os teóricos que receberam destaque nas discussões a respeito da criatividade, realizadas pelos autores das produções científicas por nós analisadas foram: Teresa Amabile, Mihalyi Csikszentmihalyi; Todd Stemberg e Robert Lubart; e Albertina Mitjáns Martínez³.

Stemberg e Lubart afirmam, em sua Teoria de Investimento em Criatividade, que a criatividade é o resultado da confluência de seis fatores: 1) habilidade intelectual- considerada pelos autores como a capacidade cognitiva de sistematizar e redefinir problemas; habilidade para analisar quais ideias valem o desprendimento de tempo para sua efetivação e; capacidade de persuadir outros sujeitos a investirem em suas ideias; 2) conhecimento que o sujeito possui em determinada área de atuação, podendo o mesmo ser proveniente da educação formal ou de

3 Teresa Amabile, diretora de pesquisa da Harvard Business School. Graduada em Química. Pesquisa principalmente questões relativas à criatividade e a motivação no ambiente de trabalho. -Mihalyi Csiksentmihalyi, professor na Claremont Graduate University - Califórnia, trabalha as questões da criatividade pela perspectiva da chamada "Psicologia positiva", tendência que visa à apreciação das potencialidades individuais e a motivação. - Robert Stemberg, professor da Universidade de Cornell. Fundamenta seus trabalhos nos pressupostos da Psicologia Cognitiva. -Todd Lubart, Dr. Em Psicologia e Professor na Universidade de Paris Descartes. - Albertina Mitjánz Martínez, Psicóloga cubana, Doutora em Psicologia. Pesquisadora da Universidade de Brasília, investiga temas relacionados a criatividade e inovação em diferentes contextos. 
experiências informais; 3 ) estilo de pensamento diferenciado- classificado em três estilos diferentes: o legislativo, característico de pessoas que preferem formular problemas e criar novas estratégias de resolução a eles; o executivo, próprio dos sujeitos que gostam de implementar ideias com estruturas claras e bem definidas; e o judiciário, característico de sujeitos que preferem avaliar pessoas, regras, bem como emitir julgamentos e opiniões; 4) personalidade - as pessoas criativas apresentam os seguintes traços de personalidade: tolerância a ambiguidade, resistência a frustração, persistência, autoconfiança, coragem, bom humor; 5) motivação extrínseca, relacionadas ao reconhecimento social ou ao recebimento de recompensas; ou intrínseca, advinda do prazer do sujeito em realizar determinada atividade; 6) ambiente adequado, sendo este favorecedor à geração de ideias e oferecendo suporte e encorajamento ao desenvolvimento de ideias e geração de produtos (AQUINO, 2012; SOUSA FILHO, 2011).

O Modelo Componencial da Criatividade de Amabile compreende a necessidade de interação entre quatro componentes para a ocorrência de um produto criativo, sendo eles: a) habilidade de domínio, que consiste no amplo conhecimento teórico e habilidades técnicas em uma determinada área; b) processos criativos relevantes, entendido como a compreensão de processos complexos, relacionados à área em que o sujeito trabalha, flexibilidade perceptual, suspensão de julgamentos e mudança nos modos tradicionais de se pensar uma problemática; c) estilo de trabalho, que refere-se a alta habilidade de concentração por longos períodos, persistência e dedicação a tarefa, bem como a capacidade de se distanciar da tarefa que se realizada e identificar uma ideia improdutiva, na qual não valha apena persistir; d) motivação intrínseca, que se refere ao envolvimento e satisfação do sujeito com sua atividade, o que resulta em dedicação, independentemente da existência de reforços externos, como as recompensas. A teórica afirma ainda que a motivação é uma característica, em maioria, inata, mas que pode ser desenvolvida se o ambiente for favorecedor (OLIVEIRA; ALENCAR, 2012; SOUSA FILHO, 2011).

Para a Perspectiva de Sistemas de Csikszentmihalyi, a criatividade é resultado da interação entre o domínio, o indivíduo e o campo. "O domínio transmite informações ao indivíduo, e este produz variações que, por meio do campo, podem ou não ser incorporadas a esse domínio" (OLIVEIRA; ALENCAR, 2012, p. 542-543). Esta nova produção, ou seja, aquilo que o sujeito criou, para ser considerada criativa, deve passar pelo julgamento de pessoas gabaritadas, que compõem o campo de conhecimento a que a criação se destina. Tal julgamento é condicionado pela cultura e o objeto criado pode deixar de ser considerado criativo com o passar do tempo.

De acordo com Sousa Filho (2011), para Csikszentmihalyi, existe uma motivação típica para a criatividade, resultado da combinação entre interesse pessoal e "um senso de 
que alguma coisa é periférica no ambiente intelectual" (SOUSA FILHO, 2011, p. 20), bem como é necessário que o sujeito tenha prazer em descobrir coisas novas. A este prazer, Csikszentmihalyi denomina: Flow. Este corresponde a um estado de condições perfeitas ao desenvolvimento daquilo que o sujeito criador se propôs a desenvolver, em que os objetivos a serem alcançados são claros ao sujeito; as etapas à sua obtenção estão bem definidas; o sujeito mantém-se focado em cumprir as tarefas sem distrações; os desafios do processo são compatíveis com as habilidades do sujeito, entre outros.

A principal característica do sujeito criativo seria a tendência em combinar ação e pensamento, capacidade que para Csikszentmihalyi, segundo aponta Sousa Filho (2011), não seria encontrada na maioria das pessoas. A pessoa criativa também teria dez traços de personalidades paradoxais: 1) ter grande energia física, mas também ser quieto e descansado; 2) ter um QI de no mínimo 120, mas acima dessa pontuação o nível de criatividade pode não depender tanto do QI, sendo a pessoa criativa esperta e ingênua ao mesmo tempo; 3) combinar divertimento com disciplina; 4) utilizar tanto a imaginação quanto o senso de realidade; 5) tem tendência tanto à introversão quanto a extroversão; 6) é tanto humilde quanto orgulhosa; 7) não se encaixa em estereótipos convencionados aos papéis masculino e feminino; 8) é imaginada como rebelde e independente; 9) é tanto passional quanto objetiva em seu trabalho; 10) é aberta e sensível, expondo-se ao sofrimento e à dor, mas também ao prazer e ao divertimento (SOUSA FILHO, 2011).

Para Mitjáns Martínez, a criatividade é compreendida como expressão da personalidade, processo considerado por ela como complexo e composto pela subjetividade individual e subjetividade social A primeira forma de subjetividade, segundo as explicações dos trabalhos analisados, constitui-se dos sentidos e significados desenvolvidos pelo sujeito ao longo de sua história de vida; a segunda forma refere-se aos discursos, crenças, padrões de relações e tradições, que regem o funcionamento de um determinado espaço (ANACHE; FERNANDES, 2015; ARRUDA, 2014; TÁVORA, 2010). Segundo Távora (2010) e Arruda (2014), Martínez afirma existir configurações subjetivas específicas relacionadas à criatividade, tais como: nível elevado de motivação para a profissão, clara orientação de futuro no campo profissional, autovaloração, orientação muito ativa para superação profissional.

As produções analisadas não expuseram como as características necessárias a criatividade, apontadas pelos teóricos acima mencionados, se desenvolvem, destacando apenas a necessidade de existência das mesmas. Julgamos necessário que o desenvolvimento destas características seja discutido, pois é com base nelas que os profissionais, que adotam um modelo ou outro, podem organizar seu trabalho de modo consciente, distinguindo o que precisa, ou não, ser alterado, para atingirem seus objetivos. Entretanto, importante salientar 
o modo como tais características foram apresentadas. Os autores das referidas teorias não estabeleceram correlação entre as diversas realidades sociais e o desenvolvimento do psiquismo e, logo, das capacidades exigidas à criatividade, deixando a cargo do indivíduo a responsabilidade de desenvolver tais características. Considera-se os indivíduos como sujeitos ativos em suas relações, cabendo a estes a responsabilidade e comprometimento com seu trabalho. No entanto, as condições de acesso ao conhecimento, a qualidade e quantidade das apropriações que lhe foram oportunizadas ao longo de sua história de desenvolvimento, as condições concreto objetivas de acesso a recursos materiais para a cristalização do imaginado, entre outras condições favorecedoras a criatividade são questões que não podem ser ignoradas, nem ficarem a cargo da responsabilidade individual. É necessário problematizar os motivos da existência, ou ausência, de características cognitivas e afetivas nos sujeitos, problematizar e discutir o porquê de alguns sujeitos desenvolverem certas habilidades e outras não. Ao elencarmos quais funções psicológicas e características da personalidade são fundamentais, ou ganham destaque, na realização de uma atividade, devemos trazer à tona como estas se desenvolvem e quais as possibilidades de desenvolvimentos das mesmas nos diferentes contextos sociais, com seus diferentes estímulos e possibilidades. $O$ que não aprece nas teorias que se propõem a explicar o desenvolvimento da criatividade.

Expusemos neste tópico a compreensão geral do que seja a criatividade, para os teóricos mais utilizados nas produções científicas que analisamos. Apresentaremos agora como os autores das produções analisadas, a partir das teorias por eles adotadas, compreendem o desenvolvimento da criatividade, na especificidade da prática pedagógica.

\subsection{Determinantes da criatividade na prática pedagógica}

Entendemos que toda atividade tem sua especificidade, ou seja, que exige o desenvolvimento de capacidades específicas e o domínio de instrumentos materiais e simbólicos a ela relacionados, para que possa ser executada. Deste modo, foi interesse de pesquisa identificar como os autores das produções científicas analisadas compreendem a especificidade do desenvolvimento da criatividade dos professores em sua prática pedagógica, o que eles consideram como determinante ao desenvolvimento da criatividade do professor.

Fadel (2010), Nuñez e Santos (2012) e Sousa Filho (2011) destacaram a necessidade dos professores, por meio de seus espaços formativos, compreenderem o processo criativo, considerando que tal entendimento colaboraria significativamente ao desenvolvimento de sua própria criatividade, bem como da criatividade dos seus alunos. Consideramos que o ensino teórico do que seja a Criatividade não estabelece correlação direta com o desenvolvimento desta função psicológica nos sujeitos. Para que isto ocorra é necessário 
que estes conheçam com profundidade o objeto de seu trabalho e os fenômenos com quais estes se relacionam. Távora (2010) e Arruda (2014), baseadas nos escritos de Mitjáns Martínez, consideraram, como importante para a criatividade na prática pedagógica, os "recursos subjetivos" do professor, referentes à sua atividade de trabalho. Estes correspondem a compreensão que os sujeitos têm sobre o que seja ser professor e a vinculação afetivo-emocional estabelecidas com seus alunos. Tais fatores possibilita que os professores tenham objetivos pessoais relacionados a prática pedagógica, sendo estes capazes de motivá-los a romper com as tradicionais práticas de ensino.

Mitjáns Martínez, segundo Arruda (2014), destaca o papel da motivação para ensinar como fundamental ao desenvolvimento da criatividade do professor. A teórica adota o conceito de motivação desenvolvido por Gonzalez Rey, para quem "a motivação é um tipo de configuração subjetiva que está na base da produção de sentidos subjetivos comprometidos com a ação na atividade concreta, define-se no sujeito e pelo sujeito, e não pelo tipo de atividade" (ARRUDA, 2014, p. 68).

Compreendemos que os fatores afetivo-emocionais do professor em relação a sua profissão e aos alunos são considerados, na teoria de Mitjáns Martínez, como responsáveis por motivar o sujeito a criatividade, de modo que, na ausência de tais afetos positivos, fica inviável o desenvolvimento da criatividade. Com base nos pressupostos da Psicologia Histórico-Cultural, compreendemos que a necessidade é fundamental a todas as atividades. A inexistência do objeto que satisfaça uma carência social, afetiva ou orgânica é o que o instiga os homens a agirem de modo a transformar a realidade, na busca de tal objeto (LEONTIEV, 1978; VIGOTSKI, 2009). No entanto, a necessidade não possibilita ao sujeito as condições necessárias para que ele possa planejar e se orientar de modo a alcançar o objeto de sua necessidade. Tal papel é exercido pelo próprio objeto, denominado por Leontiev (1978) de motivo. É o motivo, por suas características, que regulará as ações do sujeito ao seu alcancequando o objeto da necessidade já existe na realidade; ou na criação do objeto quando aquilo que já existe na realidade, não é capaz se suprir a necessidade do sujeito.

O alcance ou a criação do objeto da necessidade se realiza em etapas, as quais Leontiev denomina ações. Este caminho a ser percorrido, ou seja, a realização da atividade de criação do objeto, tem, para o sujeito, um sentido pessoal, uma razão que justifica para o próprio sujeito aquilo que ele está realizando. Tal como a necessidade e o motivo, o sentido pessoal é constituído na relação do sujeito com os fenômenos e os objetos da realidade e está ligado ao que o este sujeito necessita, com aquilo que ele realmente pretende alcançar. As ações da atividade, ou seja, os meios para alcançar o objeto, não estabelecem relação direta com o sentido pessoal (LEONTIEV, 1978). 
Assim sendo, imaginemos o professor que tem como necessidade se destacar em sua prática profissional e ser reconhecido pelos seus pares como alguém qualificado e dedicado. Nesta situação, a razão pela qual este professor se esforça para ser criativo, ou seja, o sentido pessoal, não é que seus alunos aprendam, mas sim sua necessidade de ser apreciado pelos seus pares. Deste modo, consideramos que a criatividade na prática pedagógica não depende da vinculação afetivo-emocional do professor, seja com sua prática, ou com seus alunos. Os professores podem ter necessidades das mais diversas ordens: necessidades de promover o desenvolvimento dos alunos; necessidade de ser reconhecido pela excelência no trabalho que realiza; necessidade em receber recompensas materiais por trabalharem de modo diferente do usual, entre outras. Deste modo, a criatividade pode ser uma atividade fim ou apenas um meio, utilizado pelo professor para alcançar o objeto da sua necessidade. Consideramos, portanto, que a existência de uma vinculação afetiva positiva, aos alunos e/ou a sua profissão, não assume papel determinante para a criatividade na prática pedagógica ou em qualquer outra atividade criativa.

Com o exposto, nota-se que a criatividade, de um modo ou outro, tem sido atribuída ao desenvolvimento de uma ou outra característica pessoal dos indivíduos, seja ele cognitiva, ou afetiva, desenvolvidas via treinamento de habilidades, discussões teóricas a respeito do que seja a criatividade; ou à motivação intrínseca desses sujeitos em relação a prática pedagógica. Contrariamente, compreendemos que, tal como o desenvolvimento das demais funções psicológicas, a criatividade resulta da relação dialética entre fatores cognitivos, afetivos, e emocionais, condicionados às condições sociais da classe social a que o sujeito pertence e ao seu tempo histórico.

\subsection{As práticas pedagógicas criativas}

Buscou-se identificar, nas produções que forneciam relatos de práticas pedagógicas, quais foram as ações, consideradas pelos autores, como criativas.

Os relatos de campo da tese de doutorado de Arruda (2014) demonstraram que a pesquisadora considerou como criativas atitudes como: o interesse do professor pela história de vida dos alunos; a solicitação de alunos para ajudar na realização de tarefas, com o intuito de envolvê-los afetivamente nas atividades acadêmicas; utilização de estórias, músicas e lendas para discutir sobre questões morais; a participação dos alunos na discussão de como realizar as atividades.

Sforni $(2004 ; 2015)$ chama atenção para ações como estas que, apesar de bem-intencionadas e aparentemente criativas, não contribuem para formação do pensamento 
teórico-científico nos alunos, não se diferenciando, deste modo, o aprendizado cotidiano do ensino sistematizado. A autora ressalta, ainda, que atividades que objetivam a discussão e ensino de questões éticas, cívicas, morais entre outras podem ser trabalhadas na instituição escolar, mas que não deve ser este o foco da mesma.

Sousa Filho (2011), para sua dissertação de mestrado, propôs um treinamento aos professores, objetivando desenvolver a criatividade dos mesmos. Dentre os exemplos da didática utilizada pelo grupo de professores participantes do treinamento de criatividade oferecido pelo pesquisador, e considerada por ele como criativa, está a elaboração de receitas, no intuito de auxiliar, a partir das características externas dos objetos e ingredientes utilizados, na capacidade de identificação, diferenciação e classificação dos mesmos.

Participante 2: (plano de aula 5 do anexo 3) O tema foi "Lanche". Os alunos estão
elaborando um caderno de receitas (...). A atividade do dia é bolo de cenoura. A pro-
fessora faz um quadro com os ingredientes de um lado e com itens como tamanho,
forma, quantidade de porções de outro. Questiona as crianças sobre quais formas
poderia ter o bolo, qual tamanho, para quantas pessoas, o que poderia ser utilizado
se faltasse cenoura, o que poderia ser combinado com ela, o que poderia ser elimi-
nado (SOUSA FILHO, 2011, p. 122).

Os exemplos de prática pedagógica fornecidos por Ribeiro (2013) demonstraram que a criatividade na prática pedagógica tem sido considerada em qualquer atividade que fuja ao uso do caderno e do lápis, por exemplo, colagem de figuras em sacos de estopa, semelhante aos antigos cartazes de cartolina.

Testoni (2013) considerou como demonstração da criatividade a capacidade dos professores, sujeitos de sua pesquisa, de responder aos imprevistos que surgem no cotidiano da sala de aula, sendo estes de ordem didática ou não. Por adotar tal posicionamento, os exemplos fornecidos pelo pesquisador exemplificavam questões referentes à capacidade de, por exemplo, conseguir continuar com a exposição do conteúdo, mesmo após o apareIho audiovisual parar de funcionar.

As produções teóricas analisadas variaram em objetivos e métodos de pesquisa, por este motivo nem todas forneceram dados que possibilitasse a identificação de ações pedagógicas consideradas criativas.

3.4. Qualidade das apropriações dos professores e possibilidade de desenvolvimento da criatividade

Como exposto, o desenvolvimento cognitivo alcançado pelo gênero humano não é transmitido aos indivíduos da espécie por vias genético-hereditária. Para se apropriar dos 
conteúdos acumulados e sistematizados ao longo da história da humanidade e, consequentemente, alcançar níveis elevados de desenvolvimento, os sujeitos necessitam estar em uma atividade educativa. A educação formal, qualitativamente superior à educação cotidiana, ao cumprir seu objetivo de desenvolver nos sujeitos o pensamento teórico-conceitual, capacita-os a pensar o mundo sob uma perspectiva mais ampla e profunda, habilitando os indivíduos, que dela participa, imaginar, pensar, planejar e executar formas complexas de modificação da realidade. A riqueza da depende da qualidade das apropriações que o sujeito obteve ao longo de sua história individual, e as condições materiais determinam as possibilidades de sua cristalização (PETROVSKI, 1980; VIGOTSKI, 2009).

Partindo desta compreensão, destaca-se a importância do domínio, pelo professor, dos conteúdos que se propõe a transmitir. Fator que exige uma formação acadêmica que o instrumentalize a atividade pedagógica de qualidade, bem como que seja possível o constante aprimoramento, desenvolvendo assim um pensamento que o habilite a promover atividades pedagógicas criativas, que propicie o aprendizado do aluno. Por este motivo, buscaram-se identificar, nas produções analisadas, informações que possibilitasse inferir sobre a qualidade das apropriações e condições de trabalho dos professores, e as consequências destas sobre a possibilidade de atuações criativas.

Arruda (2014), ao entrevistar professoras da rede pública do Distrito Federal, apresentou dados referentes à dificuldade de formação de algumas delas, como o fato de ter que conciliar estudo, trabalho e maternidade o que, na fala de uma das entrevistadas, a impedia de perceber a "articulação entre os estudos realizados em sua graduação e sua prática profissional” (ARRUDA, 2014, p. 109).

Os relatos de professoras apresentados por Távora (2010) revelaram que alguns professores não compreendem a importância do permanente enriquecimento cultural e aperfeiçoamento formativo e as consequências disto para a riqueza de sua imaginação, pensamento e, logo, nas possibilidades de criação: "pela falta de tempo acabo não estudando e não lendo! Eu não gosto de ler. (...) Aliás, não preciso ler, meu trabalho é ensinar a escrever e ler. Para que ler tanto se nem somos valorizadas para isto" (TÁVORA, 2010, p. 66).

Oliveira e Alencar (2010), em pesquisa realizada com gestores e orientadores educacionais, buscaram identificar elementos inibidores e facilitadores à prática pedagógica criativa. Dentre os elementos citados por elas estão: a falta de material para a realização do trabalho e o comodismo de alguns professores em repetir as mesmas atividades há anos. Compreende-se que o constante aprimoramento teórico, inevitavelmente, transforma a prática e que o fato destas profissionais permanecerem estagnadas em sua prática, conduz a 
hipótese de que seu nível de apropriação também esteja comprometido.

Ao que concerne à apropriação de conteúdos, Fadel (2010) e Sousa Filho (2011) consideraram suficiente, ao desenvolvimento da criatividade dos professores, o treinamento oferecido em um programa de desenvolvimento da criatividade, desconsiderando, para tal, o domínio da didática e dos conteúdos teóricos das disciplinas ministradas pelos professores. Tais treinamentos voltam-se a desenvolver habilidades relacionadas a desenvoltura, ampliação do vocabulário, formas não usuais de utilizar um objeto, improvisação, persistência, humor dos sujeitos. Não estabelecendo relação com o objeto e o objetivo de trabalho dos sujeitos que estão sendo treinados, como se uma fórmula pudesse ser aplicada e, a partir dela, os sujeitos se tornassem criativos.

Por assim ser, considera-se que tais treinamentos trazem a compreensão da criatividade como uma capacidade que se desenvolve e se expressa do mesmo modo em todas as atividades e em todos os indivíduos, como um modelo personológico existente a priori, e ignoram questões importantes, como as possibilidades e impedimentos de apropriação de conteúdos que conduz ao domínio da práxis pedagógica. A capacitação oferecida ao professor não deve ser no sentido de treiná-lo para a criatividade, mas sim de oferecer condições de compreensão da sua atividade. É o domínio do objeto de seu trabalho que Ihe propiciará a possibilidade de pensar sobre formas criativas para sua modificação, bem como é necessário que, no desenvolvimento de sua prática, ele tenha condições materiais para executar o que imaginou e planejou. Não há como destacar determinadas característica a serem desenvolvidas para tornar os sujeitos criativos, posto que a criatividade não parte do desenvolvimento isolado de características da personalidade do sujeito, mas sim do conhecimento que ele obtém a respeito daquilo que pretende modificar.

\section{CONSIDERAÇÕES FINAIS}

Apresentou-se aqui, a Criatividade como função psicológica superior, passível de desenvolvimento em todos os indivíduos da espécie humana. Atribuiu-se tal fato a relação dialética de transformação homem/natureza, que resultou no desenvolvimento da consciência humana, possibilitando o estabelecimento de relações entre os fenômenos e objetos da realidade e a transmissão de experiência individuais à coletividade e às futuras gerações.

Pautados nos escritos dos teóricos da Psicologia Histórico-cultural, destacou-se a imaginação e a plasticidade cerebral como basilares no desenvolvimento da criatividade. Ressaltou-se, ainda, a participação do pensamento neste processo, e a correlação direta que este estabelece com a qualidade e quantidade das apropriações dos conhecimentos 
historicamente sistematizados, que possibilita ao sujeito inferir, relacionar, planejar e preparar ações a fim de modificar sua realidade.

Pode-se verificar que a compreensão de criatividade como capacidade inata, desenvolvida em poucos indivíduos, presente em muitos discursos há tempos atrás está sendo superada, pelo menos no material bibliográfico que tivemos acesso. Entretanto, não há uma discussão aprofundada sobre como as habilidades cognitivas e afetivas constituintes da criatividade se desenvolvem e que relações estabelecem com o modo de organização social a que estamos inseridos, reduzindo, deste modo, o desenvolvimento da criatividade ao mero esforço individual. Por isso, as proposições realizadas pelos autores das produções analisadas acabam por não problematizar as condições de formação e trabalho do professor, mas sim em treiná-lo a ser criativo. Treinamentos estes pautados em ideias estereotipadas a respeito de como deve ser o indivíduo criativo.

Ao que se refere à vinculação afetivo-emocional, a disposição intrínseca para agir criativamente, posta por Mitjáns Martínez como condição fundamental ao desenvolvimento da criatividade na prática pedagógica, ressalta-se que apesar da importância em se ter sentidos pessoais positivos referentes à atividade que se realiza, estes não são condição fundamental ao desenvolvimento da criatividade, estando esta condicionada ao desenvolvimento da imaginação e do pensamento, capaz de reconstruir e transformar o objeto com o que se trabalha.

Pelos exemplos fornecidos, verifica-se que as práticas pedagógicas, consideradas criativas pelos autores estudados, se aproximam bastante das ações cotidianas, as quais os alunos participam não avançando, deste modo, para além da formação do pensamento empírico. Assim, apesar de receberem status de criativas, estas práticas pedagógicas não possibilitam o desenvolvimento da capacidade de generalização e abstração e, por isso, não alcançam o objetivo da educação formal, que é o de desenvolver nos alunos o pensamento teórico-científico. Posto que, por trabalharem com um modelo de sujeito criativo, as teorias não põem em discussão a efetividade das ações, mas sim contentam-se em verificar se características e/ou ações próprias ao estereótipo de sujeito criativo estão presentes no comportamento dos professores. Fica claro, então, que a importância da apropriação dos conceitos científicos - objetivo primeiro da instituição escolar-, não aparece como preocupação dos pesquisadores ao tratarem do que consideram como expressão da criatividade do professor, deixando evidente que a mínima alteração na apresentação dos conteúdos, e mesmo a capacidade de improvisação, tem sido considerada como prática pedagógica criativa, desconsiderando qualquer relação com o desenvolvimento do pensamento teórico-conceitual nos alunos. 
Defendemos que a Criatividade é resultado do desenvolvimento cognitivo e do domínio dos meios e instrumentos que compõem a atividade que o sujeito realiza. Não resultando de fórmulas a serem aplicadas ou da mera vinculação afetiva do sujeito, seja com a atividade, seja com os sujeitos que dela participa. Não sendo, deste modo, possível o desenvolvimento de partes do psiquismo ou da personalidade, considerando tal parte como responsável pelo desenvolvimento de uma habilidade, ou de uma função psicológica tão complexa.

Ao que concerne à especificidade da criatividade do professor, considera-se que suas ações necessitam ser norteadas por teorias que expliquem o processo de desenvolvimento do pensamento teórico científico, o que capacita este profissional a reflexão do fazer pedagógico, evitando ações ineficazes e munindo-o a criar novos modos de transmissão do conhecimento. É o enriquecimento do seu saber, que se dá via formação inicial e continuada, que possibilita ao professor compreender e construir novas maneiras do fazer pedagógico, não por treinamentos de habilidades desconexas a sua realidade, ou em tentativas fortuitas de encontrar e promover o aprendizado. Por isso, faz-se necessário discutir as condições de formação e de trabalho do professor; e a qualidade e quantidades das suas apropriações, de modo a extrapolar questões concernentes ao mero esforço individual.

\section{REFERÊNCIAS}

ANACHE, A. A.; FERNANDES, V. L. P. Manifestações da criatividade no trabalho pedagógico do professor de artes visuais. Psicologia Escolar e Educacional, Maringá, v. 9, n. 1, 2015. Disponível em: <http://dx.doi.org/10.1590/2175-3539/2015/0191793>. Acesso em: 23 jun. 2016.

AQUINO, R. A. C. Percepção de Professores e Estudantes do Curso de Pedagogia sobre o ensino promotor da criatividade. 2012. Dissertação (Mestrado em Educação) - Universidade Católica de Brasília, Brasília. Disponível em: <https://bdtd.ucb.br:8443/jspui/handle/123456789/704>. Acesso em: 30 mar. 2016.

ARRUDA, T. S. A criatividade no trabalho pedagógico do professor e o movimento em sua subjetividade. 2014. Tese (Doutorado em Educação) - Universidade de Brasília, Brasília, 2014. Disponível em: <http://repositorio.unb.br/handle/10482/17574>. Acesso em: 25 jun. 2016.

FADEL, S. J. Avaliação de Um Programa de Criatividade Para Professores no Ensino Superior. 2010. Tese (Doutorado em Psicologia). Pontifícia Universidade Católica, Campi- 
nas. Disponível em: <http://tede.bibliotecadigital.puc-campinas.edu.br:8080/jspui/handle/ tede/419>. Acesso em: 30 mar. 2016.

GUREVICH. K, M. EI Pensamiento. In: SMIRNOV, A. A.; RUBINSTEIN S. L., LEONTIEV A. N.; TIEPLOV B. M. (Orgs.). Psicologia. México: Tratados y Manuales Grijalbo. 1978.

LEONTIEV, A. N. O Desenvolvimento do Psiquismo. Lisboa: Livros Horizonte, 1978.

LURIA, A. R. Curso de Psicologia Geral. Rio de Janeiro: Civilização brasileira. 1979.

LURIA, A. R. Desenvolvimento Cognitivo: Seus Fundamentos Culturais e Sociais. São Paulo: Ícone, 2008.

Martins, L. M. O Desenvolvimento do Psiquismo e a Educação Escolar: Contribuições à Luz da Psicologia Histórico-Cultural e da Pedagogia Histórico-Crítica. 2011. Tese (Livre-Docência). Universidade Estadual Paulista, Bauru-SP.

NUÑEZ, I. B.; SANTOS, F. A. A. O Professor e a Formação Docente: a Criatividade e as Crenças Educativas Onde Estão? Holos, Natal, v. 2, 2012. Disponível em: <https://doi. org/10.15628/holos.2012.797>. Acesso em: 23 jun 2016.

OLIVEIRA, E. E. L; ALENCAR, E. M. L.S. Criatividade e Escola: Limites e Possibilidades Segundo Gestores e Orientadores Educacionais. Revista Semestral da Associação Brasileira de Psicologia Escolar e Educacional, São Paulo, v. 14, n. 2, 2010. Disponível em: <http://dx.doi.org/10.1590/S1413-85572010000200007>. Acesso em: 23 jun 2016.

PEIXOTO, K. N. Criatividade: uma fundamentação histórico-cultural na busca da gênese e compreensão do desenvolvimento deste fenômeno. In: $3^{\circ}$ Congresso Internacional sobre a Teoria Histórico-cultural e $15^{\text {a }}$ Jornada do Núcleo de Ensino de Marília. 2016, Marília-SP. Anais... Marília: UNESP, 2016. Disponível em: <http://www.inscricoes.fmb.unesp.br/ upload/trabalhos/2017418172853.pdf>. Acesso em: 01 jul. 2018.

PETROVSKI, A. Psicologia General. Moscú: Editorial Progresso, 1980.

RIBEIRO, E. Pesquisa e Criatividade na Formação do Professor de Geografia. Geografia Ensino \& Pesquisa, Santa Maria, v. 17, n. 2, 2013. Disponível em: <https://periodicos. ufsm.br/geografia/article/view/10775>. Acesso em: 23 jun. 2016.

RUBINSTEIN, S. L. Princípios de Psicologia General. México: Editorial Grijalbo, 1967.

SOUZA FILHO, P. G. Desenvolvimento da criatividade em ambientes digitais em professores dos anos iniciais do Ensino Fundamental. 2011. Tese (Doutorado em Informática na Educação) - Universidade Federal do Rio Grande do Sul, Porto Alegre. Disponível em: 
<https://www.lume.ufrgs.br/bitstream/handle/10183/39672/000826420.pdf?sequence=1>. Acesso em: 30 mar. 2016.

SFORNI, M. S. F. Práticas pedagógicas e aprendizagem conceitual. In: V Anped Sul - Seminário de Pesquisa em Educação da Região Sul, 2004, Curitiba. Anais... (p. 01-14).

SFORNI, M. S. Interação entre Didática e Teoria Histórico-Cultural. Educação \& Realidade, São Paulo, v. 40, 2015. Disponível em: <http://www.scielo.br/scielo.php?pi$\mathrm{d}=$ S2175-62362015000200375\&script=sci_abstract\&tIng=pt>. Acesso em: 01 mar. 2018.

TÁVORA, F. O. F. A expressão da criatividade no trabalho pedagógico do professor alfabetizador. 2010. Dissertação (Mestrado em Educação) - Universidade de Brasília, Brasília. Disponível em: <http://repositorio.unb.br/handle/10482/7090>. Acesso em: 30 mar. 2016.

TESTONI, L. A. Caminhos criativos e elaboração de conhecimentos pedagógicos de conteúdo na formação inicial do professor de Física. 2013. Tese (Doutorado em Educação) - Universidade de São Paulo, São Paulo. Disponível em: <http://www.teses.usp.br/teses/ disponiveis/48/48134/tde-25022014-144942/fr.php>. Acesso em: 30 mar. 2016.

VIGOTSKI, L. S. Obras Escogidas III. Madrid: Visor, 2000.

VIGOTSKI, L. S. Imaginação e Criação na Infância. São Paulo: Ática, 2009.

VIGOTSKI, L. S. A construção do Pensamento e da Linguagem. 2. ed. São Paulo: Martins Fontes, 2010. 